\title{
Desperdício de Know-How na Emprêsa
}

1. Estereotipia na Emprêsa. 2. Rigidez das Comunicaçóes. 3 Resistência ds Inovações. 4. O Fluxo das Comunicações.

A cultura em geral e o know-how em particular, embora concebidos como autênticos produtos sociais, têm sua base física nos indivíduos. É certo que os meios de transmissão de cultura e de know-how (livros, revistas, audiovisuais, etc.) podem ganhar certa autonomia: uma biblioteca, uma discoteca, uma filmoteca é uma espécie de banco de cultura, contra o qual qualquer um pode sacar. Mas, na vida prática, tôda transmissão cultural é feita por contágio, imitação, comunicação, isto é, por algum tipo de cooperação social. Para que o saber não fique estagnado ou represado, é preciso que se criem canais de circulação. $O$ dinamismo progressista de um grupo social, portanto, depende da facilitação da comunicação. A comunicação realmente eficiente é sempre interpessoal e se realiza, quase sempre, no pequeno grupo.

Quanto mais a cultura e o know-how se espalham e se tornam patrimônio social, mais alto é o padrão produtivo da comunidade. Em tôda parte, no mundo dos países desenvolvidos, há preocupação excitante pela difusão de conhecimentos e pelo rigoroso planejamento na abertura de canais de comunicação que levem a todos o máximo de informações - bibliotecas, revistas técnicas, literatura de difusão científica, programas de televisão, recursos audiovisuais, comitês, etc. Mas quase nada se faz para abrir canais dentro das emprêsas

R. Adm. Emp., Rio de Janeiro, $\quad 9$ (3): 111-118, jul./set. 1969 
e repartições e mesmo nas universidades, isto é, nos locais onde o saber se cria e para onde reflui depois de criado. Cada emprêsa apresenta-se como uma fortaleza medieval que deve ser conquistada a duras penas pelos que dela se aproximam. As observações que se seguem visam a suscitar discussão sôbre o significado e a gravidade que assume êsse problema ao incidir sôbre o funcionamento das organizações.

O grande problema, o fator que obstrui a comunicação de maneira perdulária é a estrutura arcaica da emprêsa e da repartição pública. Tudo nela se passa como se cada membro tivesse perfeita competência para sua função e sòmente êle fôsse capaz de contribuir para cumprir os objetivos traçados, o que é, òbviamente, um absurdo. E preciso não esquecer que nem tudo, no setor de produção e de organização, depende de conhecimento prévio - salvo se a padronização estagnou a criatividade. $O$ contingente de deliberação é ponderável, e a busca de soluções novas uma constante. Se uma emprêsa é dinâmica, o know-how é permanentemente pôsto em cheque pelo desafio da criatividade - invenção e descobertas.

\section{ESTEREOTIPIA NA EMPRESA}

A primeira premissa do mecanismo funcional da emprêsa é a estereotipia das funções, decorrente menos da divisão do trabalho do que de uma hierarquia de mando (heteronomia). Nada tem a ver competência com hierarquia; são duas ordens de valôres que se entrecruzam de forma inteiramente arcaica. $E$ comum na emprêsa a hierarquia obstruir a competência, prejudicando a produtividade. $\mathrm{O}$ conhecimento gera autoridade e a autoridade gera conhecimento, quando uma coisa nada tem a ver, necessàriamente, com a outra. Dêste fato geram-se conflitos insanáveis, que obstruem o progresso da tecnologia.

O indivíduo batizado, por exemplo, como datilógrafo, não é apenas um especialista em datilografia: o título corresponde também a um grau hierárquico. Jamais poderia o datilógrafo participar da reunião da diretoria... pois a suposição é de que não se trata de uma pessoa, mas de uma função especializada de tal ou qual escalão. A estereotipia sobrepóe-se à qualidade de pessoa humana, capaz de reflexões nos níveis mais altos. Ora, esta estereotipia elimina tôdas 
as demais qualidades possíveis do membro da emprêsa ou repartição, reduzindo-o a uma simples peça num mecanismo padronizado. $O$ fato de êste datilógrafo poder ser um gênio nunca é levado em consideração, de modo que a estrutura pré-fabricada esmaga tôdas as possibilidades de cooperação além do nível e da forma estabelecidos a priori, como se o indívduo jamais mudasse e fôsse incapaz de criatividade e deliberação.

Ora, pode acontecer que um datilógrafo (para a emprêsa, apenas um robô) seja um gênio, tenha várias outras aptidões, esteja cursando uma faculdade, seja ótimo jogador de xadrez, cultive em casa uma horta... Quem pode, a priori, dizer quem é, verdadeiramente, aquêle indivíduo chapeado de datilógrafo? Enquadrado numa estereotipia, dêle só aflora a datilografia, vez que é apenas isso que dêle se solicita. Pode-se imaginar o acervo de cultura e know-how que se perde porque não há flexibilidade no uso das pessoas... Se os milhares de operários de uma fábrica fôssem tomados como indivíduos inteligentes, criativos, com experiência vital altamente diversificada, o sistema de produção e de organização estaria em permanente trepidação evolutiva. O que acontece é, justamente, o contrário: cada um deve dar apenas o que lhe foi solicitado, como acontece com uma máquina programada para determinada tarefa. Tôda riqueza da energia e da criatividade humanas é perdida diante da rigidez da estrutura pré-fabricada da emprêsa ou do regulamento. A melhor parte da criatura humana - seu poder de invenção e de motivação - é criminosamente desperdiçada pela robotização das linhas de produção e pelos esquemas organizacionais.

\section{RIGLEZ DAS COMUNICAÇÓS}

Se o preconceito da hierarquia não obstruísse os canais de comunicações, tôdas as potencialidades do datilógrafo seriam usadas em vista da produtividade. Em todos os momentos críticos, e talvez sistemàticamente, todos os membros da emprêsa poderiam ser checados; imagine-se que acervo de cultura e know-how não surgiria de um sistema assim aberto! Criaram-se especialistas (o pesquisador e o organizador) para substituir a rigidez do sistema, quando todos os participantes da emprêsa e da repartição poderiam ser focos ativos de criatividade se os indivíduos fôssem tomados como pessoas. Se 
fôsse possível separar o sistema hierárquico do sistema de divisão do trabalho, haveria momentos em que desapareceriam os escalóes para vigorar a mais irrestrita cooperação de base puramente pessoal.

A capacidade ociosa em matéria de inteligência, de criatividade, de know-how, de dedicação, de serviços, determinada pela forma hierárquica arcaica da organização da emprêsa, é assombrosa. Imenso potencial de energia e de saber é represado pelos denominados $\mathrm{Ca}$ nais competentes, sobrevivência da ordem pré-técnica, da época em que não havia diferenças fundamentais na experiência dos membros de uma comunidade - divisão do trabalho, especialidades, difusão cultural. Na organização arcaica, o saber não era um valor; todos os homens de uma comunidade de trabalho tinham, mais ou menos, as mesmas aptidões; o poder, pois, não decorria da capacidade técnica. A inversão do processo - atribuir poder à competência - pode gerar outros males, como o de fixar o desenvolvimento para evitar a perda de poder ou o de supor que o poder equivale à competência.

Mas, além dos problemas estruturais (ordem vertical), inúmeros problemas situacionais (ordem horizontal) obstruem, nas emprêsas, os canais de comunicação. Existe tôda uma dinâmica interna que impede a transmissão dos conhecimentos, de vez que "saber é poder", isto é, o conhecimento determina a hierarquia. Com isso, o know-how fica retido décadas seguidas nas mãos de um indivíduo que faz do segrêdo seu poder de manutenção e de dominação. Ora, o saber deve ser fluido e permanentemente evolutivo, podendo gerar-se nos indivíduos independentemente das estruturas em que está inserido. A criatividade, muitas vêzes, decorre do choque entre matrizes tradicionais que jamais tinham sido aproximadas. $O$ conhecimento tende a rotinizar-se e a impedir nôvo conhecimento. Novas configurações dos fenômenos podem resultar de confrontos imprevisíveis favorecidos pela flexibilidade dos contatos. $O$ saber, portanto, pode ser uma fonte de imobilismo, se a dinâmica não o coloca em permanente estado de questionamento.

Quando, fora da emprêsa, o know-how já caminha para níveis mais elevados, os donos da tecnologia interna da emprêsa opõem obstáculos instransponíveis à modernização, de vez que a mudança tecnológica geralmente implica mudanças nas áreas de poder e nas hierarquias arcaicas. A mudança se torna, então, impossível, ou implica uma 
violentação de posições e de status adquiridos. Daí o interêsse geral na manutenção da rigidez dos canais internos de comunicação e as barreiras criadas contra a introdução de novos elementos na estrutura. Todo progresso científico e tecnológico enfrenta, fatalmente, essas resistências que nada têm a ver com a validade do saber, pois decorrem da estrutura de poder.

Mesmo que certas áreas dentro da emprêsa sejam sensíveis à mudança, nas demais o processo é obstruído, quando fere o espaço vital em que se localiza o status ou o prestígio de indivíduos colocados em pontos-chave. Uma emprêsa pode ser vista como um arquipélago de espaços vitais em cujas ilhas se movem os responsáveis pelos status quo. Em tôrno de cada bureau ou prancheta estende-se um campo magnético fechado que resiste às mudanças gerais, embora possa ser, como tal, extremamente dinâmico. Imensa energia é perdida pelos inovadores, menos para comprovar a viabilidade e a justeza da inovação do que para quebrar o círculo de obstrução em que se fecham os que fazem de seu know-how (real ou fictício) uma fonte de poder interno na emprêsa ou na repartição.

\section{RESISTENCLA AS INOVAÇóES}

O exemplo mais típico de fechamento dos espaços vitais é a dificuldade que enfrenta um novato para penetrar nas emprêsas; é comum a flutuação dos novatos, de emprêsa em emprêsa, até obterem uma abertura. O preço da assimilação do novato é a desistência de inovações, o que determina uma seleção negativa: quanto mais competente o novato, mais perigoso. Falta ser ensinado nas escolas profissionais como aparentar incompetência - "bancar o peixe morto" - condição de acesso às emprêsas e às repartições! Todos os recém-formados, tendo adquirido nas escolas know-how nôvo, enfrentam dificuldades, por vêzes intransponíveis, para inserir-se nas emprêsas e repartições. Pode-se imaginar o que perde a humanidade tôda em matéria de dinamização do progresso na medida em que as emprêsas e as repartições se fecham como fortalezas às inovações de know-how e às frustrações das novas gerações de técnicos diante das áreas de dominação dos representantes do poder interno das organizações. $O$ progresso é permanente batalha entre o Poder e o Conhecimento Nôvo. 
Nas grandes emprêsas, essas áreas de prestígio e ilhas de dominação são, muitas vêzes, solidificadas por configurações topológicas salas, banheiros, refeitórios, roupas, móveis privativos - de tal modo que a informação não circula além do espaço vital. Neste sentido, as barreiras psicológicas transformam-se em obstáculos físicos. Os indivíduos que, pela natureza de sua função, têm acesso a essas áreas, ganham inegável prestígio junto aos escalóes mais baixos, mesmo que não possuam posição (função de secretária, por exemplo). No fundo, todo o esquema de dominação é um problema de proteção contra a informação. $E$, pois, contraditória a pretensão de organizar a escola-emprêsa ou a emprêsa-escola, pois a escola é um sistema de informação aberto e a emprêsa, um sistema de informação fechado. Poderia a emprêsa vir a ser um sistema aberto?

\section{O FLUXo das COMUNiCAÇós}

Pode-se distinguir, dentro das emprêsas e repartições, dois níveis de comunicação: a) o oficial que segue os canais dos organogramas e fluxogramas; e b) o infra-oficial que resulta das frestas das muralhas dos espaços vitais. Este último ocorre, muitas vêzes, nos lugares mais imprevistos, como corredores, elevadores, banheiros, cantinas. Quase sempre, a informação fornecida pelo segundo sistema é mais importante que as fornecidas pelo primeiro. Assim, em vez de um sistema de ampla informação, gera-se o processo de cochicho, criando uma série de níveis de informação, cada um com grau diverso de poder. Por aí se vê como a informação se pode tornar uma mercedoria em pequena ou grande escala.

A hierarquia confere poder ao chefe mas tende a isolá-lo do processo de comunicação infra-oficial (cochicho) de modo que o leva ao esgotamento de sua inspiração e ao estabelecimento de rotinas antimudancistas. Por outro lado, a preocupação com a defesa de sua posição leva-o a desconfiar de todos, criando um círculo vicioso de isolamento. Assim, o próprio processo é contraditório: o conhecimento produz poder e o poder isola seu possuidor, levando-o à progressiva desatualização. $O$ prejuízo recai sôbre a comunidade tôda, que vê o sistema de produção e de organização esclerosar-se. Daí, talvez, a tendência à direção colegiada em que a troca de conheci- 
mento se torna a própria condição de condução da emprêsa. Mas a direção colegiada na cúpula é apenas o primeiro passo para a ampla circulação da informação em todos os escalões.

A autoridade do chefe é cerceada pela moral do grupo, espécie de solidariedade tácita que limita o poder de dinamização e de dominação da hierarquia. O prêmio ou castigo, por vêzes, são impotentes para quebrar esta aliança - por exemplo, ninguém aumentará a produtividade além de certo limite. Criam-se assim duas áreas: os altos escalões e os baixos escalões, cada uma com seu próprio código de comunicações. Em vez de ser uma máquina de produção, altamente eficiente, centrada em seus objetivos, a emprêsa transforma-se numa arena em que se digladiam os vários escalóes esfôrço da cúpula contra a operação tartaruga.

A quebra dessa ordem passa a ser a suprema traição, estigmatizada com expressões como dedo-duro, peixinho, etc. E como se se tratasse de uma guerra de sobrevivência em que a adesão ao inimigo é a culpa máxima. ${ }^{1}$ Certas organizações mantêm, institucionalmente, espias dentro dos escalóes mais baixos, justamente para quebrar essa solidariedade. Muito melhor solução seria a quebra das barreiras à comunicação. A participação na deliberação gera a solidariedade e cria a responsabilidade. Os indivíduos buscam menos o lucro que o auto-respeito. A democratização das emprêsas e repartições daria a elas a textura de unidades de produção em vez de arena de conflitos. A solidariedade nos baixos escalões é uma forma de defesa da dignidade humana que gera a hostilidade contra a dominação.

Há uma função de caráter ambivalente e ambíguo - a do capataz que se situa entre as duas faixas, perdendo a confiança dos dois pólos. Sua tarefa principal é a de comunicação nas duas direções (relais), tornando-o indivíduo odiado e isolado pelos companheiros - geralmente, sua função representa um acesso da classe inferior para a superior. O capataz é o próprio representante de uma estrutura de emprêsa: quanto mais destacada sua função, como a do feitor nas fazendas, mais arcaica a organização. E evidente que existe uma infinidade de níveis de capatazia, o grupo social que termina constituindo a chamada classe média. A capatazia diminui de

1 Ver: Conflitos no Lar e na Escola, Editôra Vozes.

Julho/Setembro 1969 
importância na medida em que a organização vertical é substituída pela organização horizontal - dinâmica de grupo. A função de capataz é um produto da desinformação.

Ora, todos êsses fatos criam profundos problemas de relações humanas, transformando as emprêsas e repartições em campo de batalha onde se entredevoram os chefóes entre si e os subordinados com os chefes, com enorme desperdício de energias vitais e de know-how. Por que não abrir os canais de comunicação em tôdas as direções de modo que tornem insustentáveis êstes conflitos? Para isto, teriam que ser continentalizados os arquipélagos de informações, fazendo todos participarem de tudo. Com o tempo, o know-how tornar-se-ia patrimônio da comusidade tôda, minimizando o poder do especialista. $^{2}$

Dinâmica de grupo é, justamente, uma solução. Todos os membros da emprêsa são tomados como pessoas e não como estereótipos. Todos são consultados e informados, de modo que o know-how da emprêsa se torne um patrimônio comum, e a experiência de campo, um patrimônio da emprêsa. As funções são meras divisões de trabalho que não determinam capitis diminutio, perda de status, de prestígio e de participação. Pode-se imaginar quanta energia e know-how serão drenados assim para a produtividade, fazendo da organização uma forma de realização pessoal de cada um.

LAURo de Oliveira lima

2 Em Cibernética e Sociedade, Nonbert WiENER sustenta que a integridade dos canais de comunicação interna é essencial para o bem-estar da sociedade (p. 129). 